\title{
Effectiveness of Self Instructional Module regarding Emergency Management of patient with Myocardial Infarction on Knowledge among Staff Nurses
}

\author{
Binu Xavier \\ Lecturer, SUM Nursing College,(SOA University) Kalinganagar K-8, Ghatikia, BBSR, Odisha,India
}

\begin{abstract}
A quasi experimental study with one group pretest and posttest without control group design was undertaken in Vinayaka Missions Hospital, Salem to assess the effectiveness of self instructional module regarding emergency management of patient with myocardial infarction on knowledge among staff nurses

Data was collected from 98 staff nurses selected by convenient sampling technique using closed ended questionnaire from 19.09.2009 to 02.10.2009. Data was analyzed by using descriptive and inferential statistics. Demographic characteristic reveals that the highest percentage (69\%) of the staff nurses were in the age group of 21-25 years, were females (74\%) were having B.Sc. nursing degree (80\%). Highest percentage were having 3-4 yrs years of experience (69\%), were working emergency unit (3\%), ICU (20\%), and general ward(29\%) and other wards (48\%) and did not attend in-service program (93\%).

The overall pretest mean score $22.06 \pm 1.92$ which is $48 \%$ whereas in the post test the mean score $(30.04 \pm 2.82)$ which is $65 \%$ of the total score with an overall difference of $17 \%$ of pretest score reveals good knowledge.

Highly significant difference found between the pretest and posttest $K S(P<0.01)$ but no significant association was found between the posttest KS when compared with the demographic variables of staff nurses $(P<0.05)$.
\end{abstract}

Key Words: Effectiveness, self instructional Module, myocardial Infarction, staff Nurses

\section{Introduction}

The heart is a four-chambered hollow muscular organ approximately the size of a fist. The heart lies within the thorax between the lungs in the mediastinal space. The heart is composed of three layers: a thin inner lining, 'the endocardium', a layer of muscle, 'the myocardium'; and a fibrous outer layer, 'the epicardium'. The heart is divided vertically by the septum, and it creates right and left atrium and ventricle.(Lewis M. Sharon, 2000)

The myocardium is composed of specialized cardiac muscle found only in the heart. It is not under voluntary control, but like skeletal muscle, cross stripes are seen on microscopic examination. The heart is supplied with arterial blood by the right and left coronary arteries which branch from the aorta.(Anne Waugh, 2002)

Coronary artery disease (CAD) is a type of blood vessel disorder that is included in the general category of atherosclerosis. Atherosclerosis is often referred to as "hardening of the arteries" which is an abnormal accumulation of lipid or fatty substances and fibrous tissue in the vessel wall. These deposits, called atheromas may rupture and forms 'the thrombus' that obstruct blood flow, leading to sudden cardiac death or an acute myocardial infarction (MI) which is the death of heart tissues.(Smeltzer C. Suzanne, 2004)

The American Heart Association (AHA, 2000), reports that an estimated 1.1 million Americans will have an acute myocardial infarction (MI) in 2003 and 460, 000 will die, half of them before reaching a hospital.

As cardio vascular disease remain the most common cause of death in both developed and developing countries, all health professionals including nurses should know the risk factors, preventive measures and its management.

\section{Need for the study}

Cardio Vascular disease is the common cause for death. The major form of cardio vascular disease is coronary artery disease, manifested as myocardial infarction, angina pectoris or sudden cardiac death. (Rosefeld G., 2004)

Myocardial Infarction (M.I) is a life threatening condition characterized by the formation of localized necrotic areas within the myocardium. M.I. usually follows the sudden occlusion of a coronary artery and abrupt cessation of blood and oxygen flow of the heart muscle.(Luckmann and Sorenson, 2000) 
The common risk factors for M.I are smoking, high B.P, too much fat in diet, diabetes, male gender, age and hereditary. Hanifield M.et.al; (2000). Evidence suggests that Reactive Oxygen species (ROS) may play important role in the pathogenesis pf myocardial infarction. (Loeper et.al, 2001)

Coronary artery disease is a world wide disease. The major form of cardio vascular disease is coronary artery disease, manifested as M.I, angina pectoris or sudden cardiac death, cause 12 million death through out the world each year. (World Health Organization, 2002)

Cardio vascular disease account for 12 million deaths annually worldwide. Myocardium Infarction continues to be significant problem in industrialized countries and is becoming an increasingly significant problem in developing countries.(Kasap et.al. 2007)

Acute myocardial infarction is one of the major causes of mortality and morbidity in the world. The most common cause of Acute Myocardial Infarction (AMI) is atherosclerotic coronary artery disease with erosion or rupture of a plaque causing transient, partial or complete arterial occlusion. (Ohja et.al, 2008)

Around 7,200,000 men and 6,000,000 women are living with some form of coronary heart disease. $1,200,000$ people suffer a (new or recurrent) coronary attack every year, and about $40 \%$ of them die as a result of the M.I. The world wide in the year of 1990, approximately 6.3 million deaths occurred due to M.I; this means that roughly every 65 seconds, an American dies of a coronary event.(American Heart Association, 2003)

Approximately 1.3 million cases of non fatal M.I. are reported each year in USA, for an annual incidence of 600 cases per 100,000 people. The proportion of patients diagnosed with NSTEMI (Non- ST segment elevated M.I) compared with STEMI (ST segment elevated M.I) has progressively increased.(National center for health statistics, USA, 2004)

M.I is the leading cause of death in industrialized western world, accounting 40.6\% all deaths in 1998 . Arlene K. (2004) . The cause of $25-30 \%$ of death in industrialized countries all due to M.I. Park.K (2004)

American Heart Association (2004) reported that, cardio vascular disease is the currently leading cause of death for Americans, each year kills approximately one third of the 1.5 million persons in the USA. The incidence of M.I were 30\% in 1997, 34\% were in 2000, and 46\% were in 2005 .

The incidence of M.I among overseas Asians, worldwide is 50\%-60\% irrespective of age, gender and socio-economic status. The mortality in Asian population suffering heart attacks is $20 \%-50 \%$, higher than the Western Population. (Young et.al, 2005)

The incidence of M.I is also increasing in Bangladesh. Rates of cardio vascular disease have risen greatly in low-income and middle income countries, with above $80 \%$ of the burden now occurring in these countries.(Yusufs, Pals P et.al, 2006)

M.I has been labeled as the single largest killer disease of the world. 40 million persons in India estimated to suffering from M.I. The hospital prevalence of M.I in India was reported to $6 \%-23 \%$, while community prevalence was reported to be $6.5 \%$ and $4.5 \%$ in urban men and women respectively.( Mahajan and Guptha ,2003)

World Health Organization has predicted that by 2015, India will have 100 million or $60 \%$ of world's heart patients. Among Indian population CVD has been reported at a very young age and in a serious form. India has gone up from $1.5 \%$ in 1960 's to about $13 \%$ at present in urban population. The increasing incidence is a part of the epidemiological transition characterized by changing life styles.

The cardio vascular disease had gone up from $2 \%$ two decades ago to $9 \%$ now in India. Even in rural areas there is considerable increase in the number of cases. The Jayadeva Institute of cardiology, Bangalore had conducted 300 free camps for cardiac checkup so far and had treated about 1.42 lakhs outpatients.( Yavangal S.T,2002)

The incidence of coronary artery disease in Tamil Nadu is nearly $50 \%-60 \%$. Many young patients present with acute coronary syndrome or acute myocardial Infarction and some of them are brought to the hospital only to be declared dead.

According to Tamilnadu government statistical report (20040, 7.94 lakhs of emergency causes were attended during the year 2002-2003. Among them 20-30\% case developed M.I.

Previous studies have supported the fact that delaying medical attention when suffering an M.I. may lead to complications such as cardiac dysrhythmia, CHF, pericarditis and rupture of heart structure. Delaying treatment times for clients suffering an acute M.I. potentially poses a disadvantage for receiving occlusion elimination therapies.(Carolyn H, 2009)

The nurses do not have adequate knowledge to interpret E.C.G. The electrodes placed on the patients by nurses were often not in the correct anatomic site which causes changes in the E.C.G. morphology and lead to misdiagnosis. The lead selected by many nurses to monitor patients is diagnostically inferior to other available leads and the lead placement is often in accurate.(Bupp J.E., 2004)

E.C.G. monitoring practice of nurses caring for patients who have suffered from M.I. showed that lead selection was inappropriate. Only $43 \%$ of the surveyed correctly identified the classic ischemia, injury and 
infarction.(Leanne A., 2002). The knowledge and skill of E.C.G. monitoring among staff nurses' shows average knowledge (42.5\%) and skill scores (29.18\%)(Shanty A.Y., 2007)

During the past decade there has been a widespread movement in the field of medicine, particularly on the part of nurses towards a more accurate and efficient treatment of acute myocardial infarction. Diagnosis, medication and treatment of M.I. errors results in thousand of adverse events and preventable reactions and deaths per year. Nurses along with other health care professionals should share the responsibility of determining how these errors occur and designing strategies on how to reduce them and in the process saving other people's lives. Knowledge of the E.C.G. patterns and its changes and interpretation can help a lot in effective nursing management of M.I.(Pearte C.A. et.al, 2006)

Ruth Rekha (2002) found in a study that teaching program are knowledge to perform emergency management of myocardial infarction, suggested that it is essential to have periodical planned teaching for staff nurses in order to reduce death among patients due to M.I.

More number of M.I. occurs in the hospital, and it is likely that the nurse in the first responder to such an emergency. Therefore nurses need to possess adequate knowledge in assessment and emergency management, which is achieved and maintained almost entirely by proper training and retraining with scientific knowledge.(Doughtery M., 2003)

Giving staff nurses an information booklet is appreciably increased the accuracy and thoroughness of their care being provided.( Sandler D.A. ,2003).Promoting health in a hospital setting in a realistic goal for acute care nurse. Nurse should be alert to life style induced diseases and risk factors that precede these diseases. (Flynn B. ,2001)

Further, during clinical experience the investigator observed that patients with M.I. are develop complication and may occur death due to less alertness. Hence the investigator wishes to develop self instructional teaching module regarding the emergency management of patients with myocardial infarction, which will improve the knowledge of the staff nurses.

\section{1)To assess the,}

\section{Objectives}

- Knowledge of the staff nurse regarding emergency management of patient with M.I., before implementation of self instructional module.

- Effectiveness of self instructional module on knowledge of staff nurses regarding emergency management of M.I.

3.2)To associate the post test knowledge scores of the staff nurses on emergency management of patient with myocardial infarction with their demographic variables.

\section{1)Research design \& Approach}

\section{Materials And Methods} approach was used.

A quasi experimental research design with pre and post test without control group and experimental

$$
\mathrm{O}_{1} \ldots \ldots \ldots-\ldots . . . . \mathrm{O}_{2}
$$

The symbols used are as follows:

$\mathbf{O}_{1}$ :- Pre test - Assessment of knowledge of staff nurses through closed ended multiple choice questionnaire, before implementation of self instructional module.

$\mathbf{X}$ : Distribution of self instructional module on emergency management of patient with myocardial infarction.

$\mathbf{O}_{2}$ :- Post test - Assessment of knowledge of staff nurses through closed ended multiple choice questionnaire, after implementation of self instructional module.

E: Effectiveness of SIM regarding emergency management of patient with myocardial infarction.

4.2) Setting Of The Study

The study was conducted in Vinayaka Missions Hospital, which is located at Chinnaseeragapady, near

to Vinayaka Mission's Annapoorana college of nursing, about $12 \mathrm{k} . \mathrm{m}$ away from Salem town. Vinayaka Missions Hospital is 410 bedded hospital and around 140 staff nurses are working in this hospital

4.3)Sample And Sampling Technique

The sample size was 98 staff nurses who were working in Vinayaka Missions Hospital, Salem.Convenient sampling technique was used to select the sample for the present study.

\section{4)Tool}


4.4.1)Closed ended questionnaire used to assess the knowledge of staff nurses regarding emergency management of patient with myocardial infarction. infarction .

4.4.2)Self Instructional Module regarding emergency management of patient with myocardial

\section{5).Planed Data Analysis}

The collected data was organized, tabulated and analyzed based on the objectives of the study by using descriptive statistics ie, percentage, mean and standard deviation and inferential statistics such as chi square and $t$ test.

The paired ' $t$ ' test was used to find out the difference in knowledge between pre and post test and chi square test was used to test the association between demographic variables with post test knowledge score. The findings of the study were presented in the form of tables and figures.

\section{Results}

Percentage wise distribution of staff nurses according to their age depicts that highest percentage (69.38\%) of staff nurses were in the age group of 21-25 years, whereas lowest percentage $(7.16 \%)$ were in the age group of $31-35$ years. However $23.46 \%$ of staff nurses were in the age group of $26-30$ years .Percentage wise distribution of staff nurses according to their gender depicts that highest percentage $(82.6 \%)$ of staff nurses were female and only (17.4\%) of the staff nurses were male.

Percentage wise distribution of the nurses according to their professional qualification in nursing shows that highest percentage $(74.49 \%)$ were degree holders, whereas lowest percentage $(25.51 \%)$ of the nurses were G.N.M. Percentage wise distribution of staff nurses according to their department of work depicts that $3.08 \%$ were working in emergency unit, $20.40 \%$ were working in intensive care units, $28.57 \%$ were working in the general wards, whereas $47.95 \%$ were working in other departments (Male and female medical and surgical ward, OPD, Ortho ward, O.T, Paediatric ward).

Percentage wise distribution of staff nurses according to their years of working experience shows that highest percentage (69.38\%) of staff nurses had $3-4$ years of experience whereas $21.42 \%$ of them had $1-2$ years of experience. Further lowest and more or less similar percentage $(6.12 \%$ and $3.08 \%)$ of staff nurses had $5-6$ years and above 6 years of experience respectively.

Percentage wise distribution of the nurses based on attending in service education program on emergency management of myocardial infarction shows that, only $7.40 \%$ of the nurses had attended in service education program, whereas most of (92.6\%) the nurses had not attended in service education program on emergency management of myocardial infarction.

The overall pretest mean score $(22.06+1.92)$ which is $48 \%$ whereas the overall post test mean score $(30.04 \pm 2.82)$ which is $65 \%$ of the total score with an overall difference of $17 \%$ reveals good knowledge. Hence it can be interpreted that the self instructional module was effective on various areas regarding "emergency management of patient with myocardial infarction.

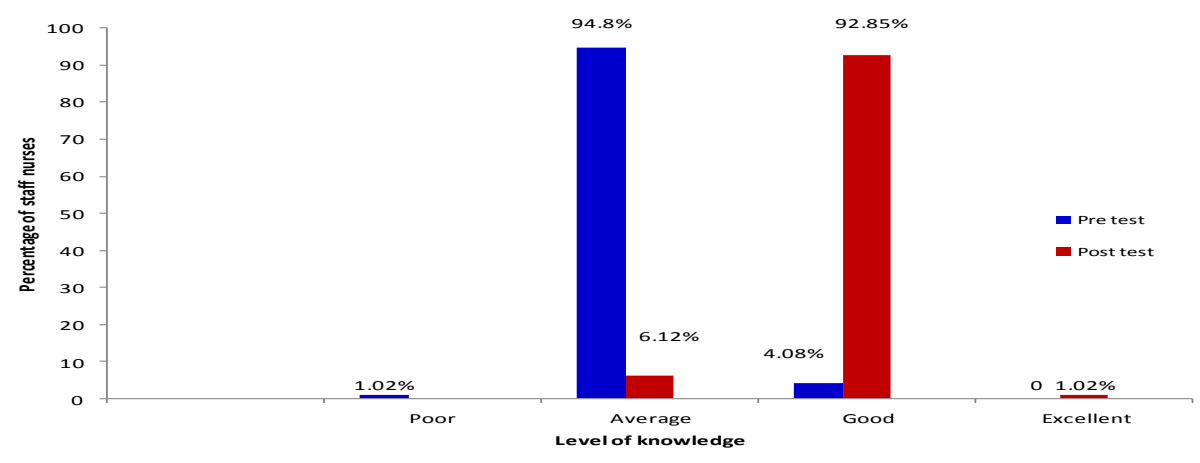

\section{Fig.5.1) Comparison of level of knowledge of pre and post knowledge scores of the staff nurses regarding emergency management of patient with myocardial infarction.}

Comparison of level of knowledge of pre and post test knowledge scores of the staff nurses(Fig 5.1) regarding emergency management of patient with myocardial infarction shows that during pre test $1.02 \%$ of staff nurses had poor knowledge, $6.12 \%$ of them had average knowledge and only $4.08 \%$ had good knowledge. Further during post test $6.12 \%$ of staff nurses obtained average knowledge, $92.85 \%$ of nurses obtained good knowledge and $1.02 \%$ of them obtained excellent knowledge. 
Chi-square values calculated to find out the association between the post-test knowledge scores and the demographic variables of the staff nurses reveals that there was no significant association between knowledge scores of the staff nurses in the post test when compared to their age, gender, professional qualification, years of experience, department of work and in-service education program

Paired ' $t$ ' value was calculated to analyze the difference in pre-test and post test knowledge scores of differentareas of emergency management of myocardial infarction shows highly significant difference between the pretest and posttest knowledge scores in all the areas.

\section{Discussion}

Highly significant difference found between the pretest and posttest knowledge scores $(\mathrm{P}<0.01)$ but no significantassociation was found between the posttest knowledge scores when compared with the demographic variables of staff nurses $(\mathrm{P}<0.05)$.

\section{Delimitation}

The study was limited to the staff nurses who were :

$>$ working in Vinayaka Missions Hospital, Salem.

$>$ of both sexes

$>$ present during the period of data collection

$>$ willing to participate in the study

$>$ completed either Diploma or Bachelor of nursing programmes

\section{Recommendations}

- A large scale study can be done for replication to standardize the self instructional module on emergency management of M.I.

- Similar study can be conducted with an experimental research approach having a control group.

- A comparative study can be carried out to generalize the finding

- A Similar study can be conducted by using self instructional module for educating the staff nurses in government hospitals to improve their knowledge regarding emergency management of M.I.

Journals

\section{References}

[1]. Agarwal .K (2007)., "An aspirin a day can keep a heart attack away in high risk patients" ; Asian journal of clinical cardiology, Vol.10, No.7, Pp:5-8.

[2]. American Heart Association. (2007). "When Every Second Counts: Cardiac Arrest and the Need for Early Defibrillation". Dallas

[3]. American Heart Association. (2005). "Management of myocardial infarction, including primary angioplasty" Circulation; 112(24_suppl): IV-35 - IV- 46.

[4]. Bartorelli A.L (2003)., Hypoxemic perfusion for treatment of reperfusion microvascular ischemia in patients with M.I, American Journal of Cardiovascular procedures; 3 (4):Pp: 253 - 263.

[5]. Bahrmann P and Rach J(2004).,Incidence and distribution of occluded culprit arteries and impact of coronary collaterals on outcome in patient with non ST segment elevation M.I and early invasive treatment strategies; Dec.14,51 (6):371 - 76.

[6]. Drew B.J (2002)., Bedside ECG monitoring, AACN clinical issues and Critical care nursing, February 4 (1), Pp: 25- 33.

[7]. Elaine K (2004)., Initial clinical results using intra cardiac electrogram monitoring to detect and alert patients during coronary plaque rupture and ischemia., Journal.Am Coll Cardiol., Sep.28: 56 (14):1089 - 98.

[8]. Henderson R.(2000)., "Comparison of two methods of teaching advanced arrhythmias to nurses; Journal of continuing nursing education, Sept - Oct; 24 (5),Pp:221 - 226.

[9]. MahajanR. and Guptha R.(2003)., Prevalence and mortality among patients with myocardial infarction, Journal of American Medical Asso.283:3223 - 3224

[10]. Zinkstok S.M, Stam .J (2009).,A randomized controlled trial of antiplatelet therapy in combination with Rt-PA thrombolysis in ischemic stroke; Trial; May 12:115 - 18 .

[11]. Wilson A.T, Channer K.S (2002)., Supplimental oxygen therapy and Morphine administration in the first 24 hour after M.I, Journl Roy. Coll physician, London,31: $657-661$.

Books

[12]. Arlene L. Polaski and Suzanne E Tatro (2004)., Luckman's core principles and practice of Med - Surg Nsg; W.B S aunder's company,Philadelphia, $4^{\text {th }}$ edition,Pp:674-706.

[13]. Black.M et al (2005),'Medical Surgical Nursing” 7thedition, volume 1,published by Elsevier a division of red Elsevier India page no-1231-1232.

[14]. Brawnwald E (2002)., Heart Disease, A Text book of cardiovascular Medicine, $5^{\text {th }}$ edition Vol.2, Harcoumt Brace and company, Philadelphia, Pp:1967 - 1985.

[15]. Crel C.A (2000)., "Understanding electrocardiography - Arrhythmias and 12 lead ECG, 5 th edition Mosby publishers, New Delhi, Pp. $85-90$.

[16]. Conill. A. et al. (2005), "Text book of critical care nursing”, J.B. Lippincott Company, Philadelphia Pp-423.

[17]. Costas Papuloukar (2003)., "Potential of an electrocardiogram for the rapid detection of coronary artery occlusion, Cardiovas. Revasc Med; Jan - Mar; 6 (1):14 - 20.

[18]. Cummins RO, Billi JE, Hazinski MF, Idris A, Ornato J, et al. (2007). 
[19]. Kothari C.R (2004)., Research methodology methods and Techniques, $2^{\text {nd }}$ edition, Newage International (P) Ltd, Pp:231.

[20]. Kuruvilla.J.(2007), “Critical care nursing", Philadelphia: W.B. Saunders Company, Pp.742-745.

[21]. Nettina M.S (2006).,Lippincott Manual of Nursing practice., $8^{\text {th }}$ edition, Jaypee Brothers Medical publishers (P) Ltd., New Delhi,Pp:252 - 253.

[22]. Perry and Potter (1994),"Clinical Nursing Skills And Techniques", $6^{\text {th }}$ edition, Mosby publication, Toronto page no. 1595

[23]. Suzanne.C.et.al.,(2004) "Text Book of Medical Surgical Nursing", $10^{\text {th }}$ edition, Lippincott Williams and Wilkins Company, Philadelphia, Pp. $533-548$

[24]. Personnet. V. et al. (2002), "Medical Surgical Nursing”, 2nd edition , Volume 2, Saunders company, Philadelphia, page no. 1703-1707.

[25]. Sethick.K.(2003), "Text book of arrhythmias", $12^{\text {th }}$ edition, Mosby publishers, Missouri, pp. 1123-1125. 